\title{
El Campo de Gibraltar a través del álbum de dibujos de Thomas Ender (1817)
}

\author{
Ana Aranda Bernal \\ Universidad Pablo de Olavide \\ amaraber@upo.es
}

RESUMEN: Al inicio de su carrera, en 1817, el pintor austríaco Thomas Ender formó parte de la expedición científica que viajó a Brasil con el séquito de la archiduquesa Leopoldina de Habsburgo. Tenía la misión de documentar el recorrido, de manera especial aquellas tierras americanas sobre las que Austria esperaba ejercer control tras el matrimonio de la joven con el heredero del trono de Portugal. La parada técnica que habitualmente se realizaba en el puerto de Gibraltar se alargó más de lo previsto, dando lugar durante el mes de mayo y primeros días de junio, a que el artista plasmara distintos aspectos del paisaje, las ciudades de Gibraltar y Algeciras, el campo de Tarifa y los barcos de la Bahía. Esas representaciones constituyen el objeto de este estudio y forman parte de un álbum, denominado "Colección Rodolfo Garcia», adquirido en 1937 por la Biblioteca Nacional de Brasil.

PALABRAS CLAVE: Thomas Ender; Algeciras; Tarifa; Campo de Gibraltar; Paisaje; Siglo XIX; Viajero; Paisaje cultural; Viaje.

\section{Campo de Gibraltar Countryside through Thomas Ender's Album of Drawings}

ABSTRACT: At the beginning of his career, in 1817, the Austrian painter Thomas Ender was part of the scientific expedition that travelled to Brazil with the Archduchess Leopoldina of Hapsburg's court. His mission was to document the journey and, specifically, that American territory over which Austria expected to exercise control after the marriage of the young Archduchess to the heir to Portugal's throne.The technical stopover that was usually made in the port of Gibraltar lasted longer than expected and, during the month of May and the first days of June, the artist captured aspects of the landscape, the cities of Gibraltar and Algeciras, the Tarifa countryside and the boats in the bay. These representations are the subject of this study and are part of an album, called the «Rodolfo Garcia Collection», acquired in 1937 by the National Library of Brazil.

KEYWORDS: Thomas Ender; Algeciras; Tarifa; Campo de Gibraltar; 19 ${ }^{\text {th }}$ Century; Landscape; Traveller; Cultural Landscape; Travel.

Recibido: 13 de febrero de 2018 / Aceptado: 2 de mayo de 2018.

En abril del año 1817 las fragatas Augusta y Austria iniciaron desde el puerto de Trieste un largo viaje, cruzando el Mediterráneo y el océano Atlántico hasta llegar a América. Se había concertado el matrimonio entre el heredero al trono de Portugal y futuro emperador de Brasil, el príncipe Pedro de Alcántara, con la archiduquesa Carolina Josefa Leopoldina de Habsburgo, hija del emperador austriaco Francisco I. Y la boda se celebraría en Río de Janeiro, donde la familia real lusa se había instalado huyendo de las guerras napoleónicas.

Para el gobierno de Austria este enlace, de indudable significación política, venía acompañado de seductoras expectativas económicas. De manera que la visión de un futuro de intervención e influencia en Brasil, considerada la más rica región del hemisferio sur, requería estudiar sus potencialidades, lo que condujo al canciller Metternich a promover un viaje de investigación sobre la flora, fauna, población y recursos brasileños.

Cómo citar este artículo: ARANDA BERNAL, Ana, «El Campo de Gibraltar a través del álbum de dibujos de Thomas Ender (1817)», Boletín de Arte-UMA, n. 39, Departamento de Historia del Arte, Universidad de Málaga, 2018, pp. 101-112, ISSN: 0211-8483, DOI: http://dx.doi.org/10.24310/BoLArte.2018.v0i39.4878 
La misión científica que debía acompañar a la archiduquesa ha sido bien estudiada y estuvo compuesta por el botánico y entomólogo J. C. Mikan, el médico y minerólogo J. E. Pohl, el zoólogo J. Natterer, así como el jardinero y botánico H. Schott. Un grupo de investigadores austríacos, al que se sumaron el zoólogo J. B. Spix y el botánico K. F. P. von Martius, de la Academia de Ciencias de Múnich (Fonseca F. Cunha, 1968).

Como es natural en una empresa de estas características, en donde la información obtenida era de la máxima importancia, los diarios de viaje de los científicos se debían completar con imágenes de todas las circunstancias que pudiera resultar útiles a proyectos posteriores. Por eso la misión se completó con dos pintores, el especialista en plantas J. Buchberger y el paisajista Thomas Ender (1793-1875).

El vienés Ender era aún muy joven, apenas tenía 20 años cuando fue enrolado en esta misión a Brasil, con la que inició los compromisos profesionales que marcarían el resto de su carrera. Pero había comenzado su formación a los doce en la Academia de Artes Santa Ana, junto a su hermano gemelo Johann Ender (1793-1854). Y ya se había especializado en la pintura de paisaje viajando por las montañas de Salzburgo, Stelemark y la región del Tirol.

Al viaje brasileño le sucedieron otros como becado a Italia y acompañando al emperador Francisco I por la propia Austria, Francia, el sur de Rusia, Turquía, Grecia y Oriente Medio. Se le incluía en las comitivas oficiales porque las autoridades requerían de sus lápices y pinceles para documentar los desplazamientos, compatibilizando esta tarea con su puesto de profesor de la Academia vienesa desde el año 1836.

A lo largo de su carrera Thomas Ender pintó numerosos óleos, pero especialmente fue desarrollando un estilo propio con la acuarela. A través de esta técnica, así como de los dibujos, se caracterizó por un trazo ágil, elegante, coloreado con habilidad y usando una amplia gama de matices. En sus obras muestra la primera impresión que le producen las escenas, con factura rápida y sensibilidad. Pero se perciben a la vez el detalle, la observación cuidadosa de las perspectivas y la reproducción del espacio urbano desde diferentes puntos de vista. Sin duda, destacó entre sus contemporáneos austriacos y a pesar de su corta estancia americana, fue uno de los mejores pintores que trabajaron en Brasil a principios del siglo XIX, razones que explican la organización en este país de una veintena de exposiciones de sus obras desde el año 1951 hasta la actualidad (Leite, 1988).

Pero volviendo a esta primera expedición brasileña, mientras en la nave Augusta viajaban miembros del séquito de la archiduquesa con algunos de los científicos, el joven pintor fue embarcado en la fragata Austria junto con Mikan, su esposa y los naturalistas bávaros. De hecho, Spix y Martius aparecen en la acuarela que muestra a los pasajeros leyendo durante la travesía [1].

El plan de ruta consistía en que ambos barcos debían dirigirse a Gibraltar y esperar allí a la escuadra portuguesa que habría recogido a Leopoldina de Habsburgo en Livorno, de manera que todos juntos continuaran la travesía del Atlántico. Así fueron bordeando las costas francesa y española, pero las circunstancias meteorológicas se complicaron durante el recorrido y, finalmente, la archiduquesa no llegó en la fecha prevista. Así que después de valorar la situación, las dos fragatas se hicieron a la mar desde el puerto gibraltareño el día 3 de junio sin esperar a la novia, que llegó en otoño a Río de Janeiro.

Durante los diez meses pasados en América, los trabajos de la misión científica se desarrollaron según lo había planificado el naturalista Karl Franz Anton von Schreibers, director de las Colecciones Vienesas de Historia Natural, en el Museo Imperial. Ello es conocido gracias a la correspondencia que mantuvo con los investigadores y los trabajos que éstos publicaron más tarde, como los diarios de viaje de Pohl, Spix y Martius, que incluyeron grabados de las ilustraciones que Ender fue ejecutando.

A través de casi setecientos dibujos a lápiz y acuarelas, muchas de las cuales realizó tras volver a Viena utilizando los apuntes de viaje, el pintor mostró la vida a bordo de la fragata Austria, panoramas del litoral, vistas de las poblaciones y sus entornos, estudios de la vegetación, animales, tipos humanos, indumentaria y, en general, los aspectos cotidianos de la sociedad brasileña.

Esas obras se guardaron primero en el Museo Imperial dirigido por von Schreibers, pero al poco tiempo se abrió al público una gran muestra que comprendía 133.000 objetos de la expedición. Para ello se ocuparon trece salas del Real Museo del Brasil en Viena, una institución auspiciada por la propia Leopoldina de Habsburgo que, desde 1822 y tras haber promovido su independencia, se había convertido en emperatriz de Brasil. Cuando esa exposición fue clausurada 


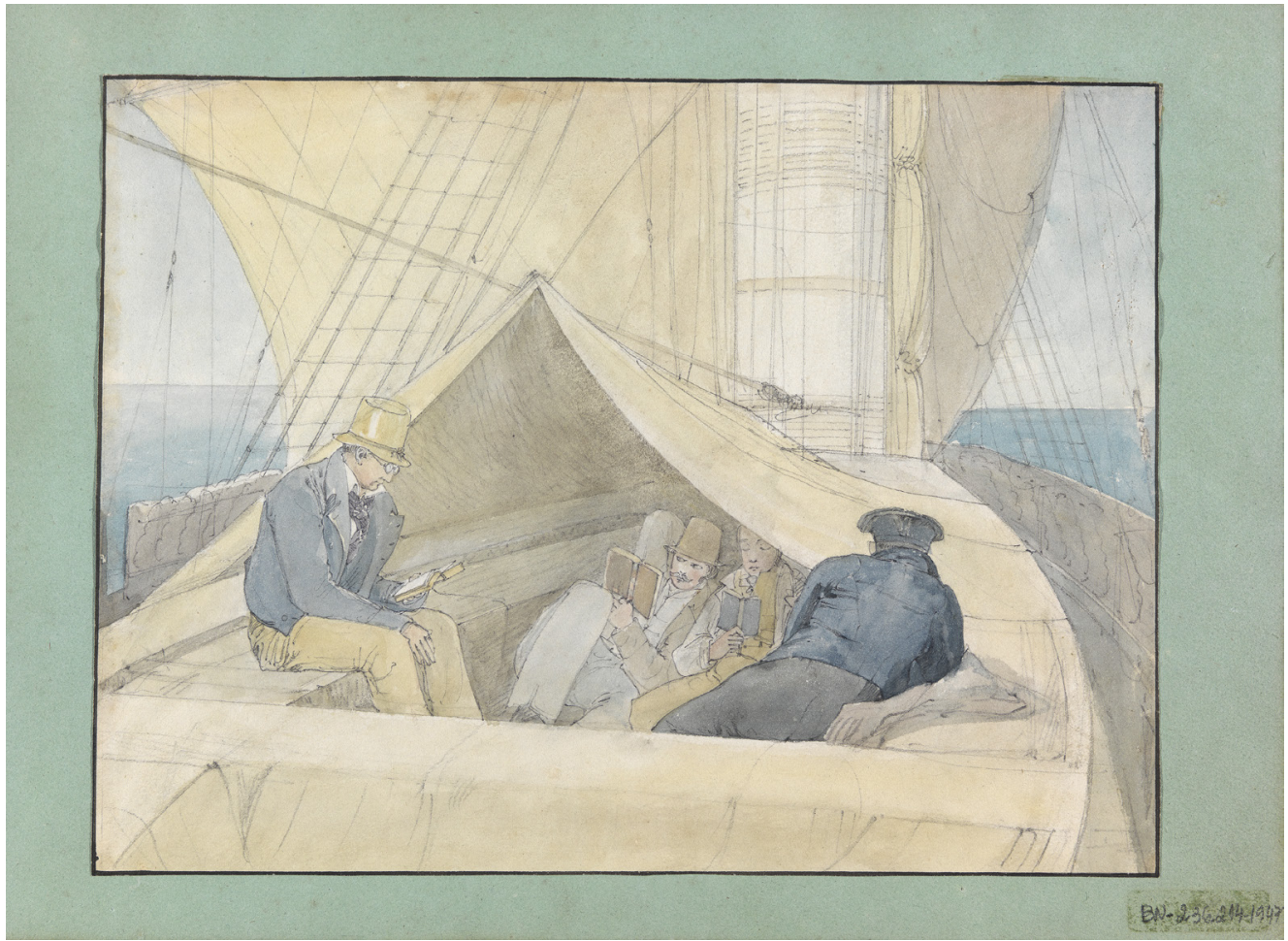

1. T. Ender, Pasajeros a bordo de la fragata Austria, 1817. Biblioteca Nacional de Brasil (BNB)

en 1836, las obras de Thomas Ender se traspasaron a la biblioteca de la Academia de Artes de Viena, en donde el artista era profesor (Fonseca F. Cunha, 1968).

Un siglo después, en el año 1937, el director de la Biblioteca Nacional en Brasil, Rodolfo Garcia, adquirió un álbum de dibujos realizados por Thomas Ender durante el viaje, con apuntes para los trabajos definitivos. Se trata de un tomo con 72 hojas numeradas, en las que se distribuyen 244 representaciones a lápiz y acuarela, con las referencias escritas al pie en alemán.

Hay algún desorden en la identificación y en las fechas, aunque la disposición de las imágenes pretende ser cronológica. Por ejemplo, una amplia y muy esquemática vista de la Bahía de Algeciras, desde Punta Carnero a la izquierda, hasta Punta Europa, aparece rotulada como la isla de Madeira [2]. Incluso alguna está datada en 1818, por lo que se haría durante la travesía de vuelta a Europa. A pesar de lo cual las primeras representaciones se corresponden con el viaje iniciado en Trieste el día 10 de abril: Italia, costas de Francia, España y África desde el Estrecho de Gibraltar, numerosas vistas de los barcos y representaciones coloreadas de las tormentas en el mar. También se reproducen vistas de las costas de Madeira, algunos roquedos y finalmente la llegada a Río de Janeiro

Ahora bien, el objeto de este artículo son las representaciones que Ender realizó mientras permanecía en la Bahía de Algeciras durante el mes de mayo y hasta la partida de Gibraltar el día 3 de junio de 1817.

Para una estancia de tantos días, no parecen demasiadas las dos docenas de apuntes que sobre este enclave geográfico se conservan en el álbum de la «Colección Rodolfo Garcia». Pero nos muestran sus movimientos marítimos y terrestres por el entorno del Estrecho, su visita a la ciudad de Algeciras y una probable excursión a la costa norteafricana. Además, se conocen varias acuarelas definitivas con panorámicas del Peñón de Gibraltar y diferentes aspectos de aquella ciudad en las que seguramente se ocupó durante ese tiempo, aunque los apuntes para realizarlas no formen parte de este cuaderno².

Desde luego, no fue un hecho excepcional que un pintor o documentalista como Thomas Ender visitase esta 


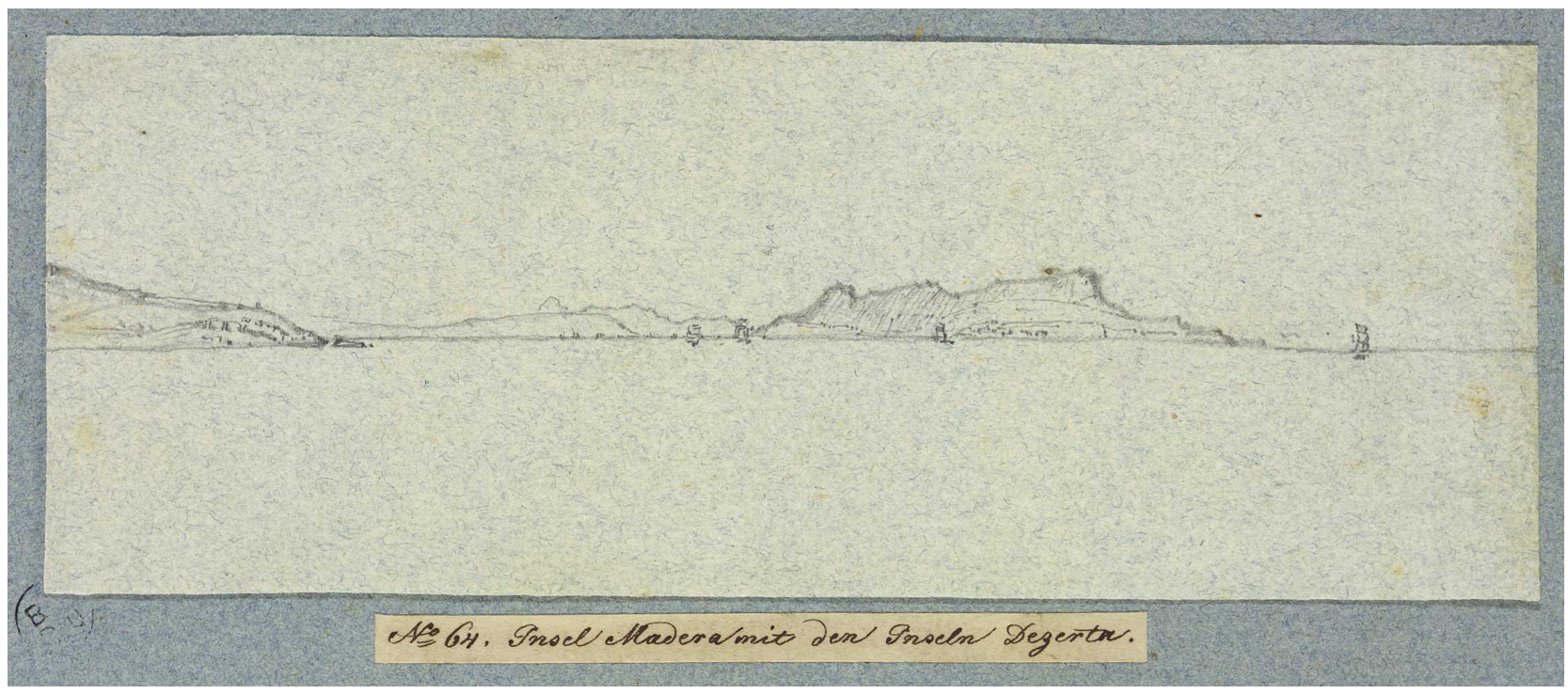

2. T. Ender, Vista de la Bahía de Algeciras y el Peñón de Gibraltar, 1817. BNB

región durante el siglo XIX y reflejase en sus trabajos las impresiones recibidas, todo lo contrario.

Este paisaje y sus habitantes fueron representados con insistencia, especialmente desde el siglo XVIII. Un hecho que se acentuó por la creciente importancia de los viajes durante el ochocientos, cuando la edición de libros sobre el tema no paraba de crecer. Con frecuencia, los escritores se hacían acompañar por ilustradores, o bien, las propias editoriales eran las que realizaban los encargos de imágenes demandadas por el público europeo.

Por otro lado, las grandes rutas marítimas tuvieron en Gibraltar una de sus escalas más importantes. Además, al margen de ser un puerto de indudable importancia estratégica y militar, el período en que Cádiz estuvo sitiada por los franceses a principios de la misma década, entre 1810 y 1812, hizo que el Peñón atrajera parte de las funciones y negocios gaditanos, especialmente en cuanto a las relaciones comerciales con América.

Aún no había llegado el momento álgido, durante la segunda mitad del siglo, cuando el aprovisionamiento de carbón para los barcos de vapor hacía ineludible la parada. Pero justo antes de adentrarse en el océano, había otros productos que acopiar para el mantenimiento de las tripulaciones y los viajeros de los veleros, lo que justificaba la espera en este puerto del extremo occidental mediterráneo. Como la realización de esas tareas requería días e incluso semanas, habitualmente los pasajeros dedicaban su tiempo a recorrer el entorno, que con frecuencia se ampliaba hasta la ciudad de Granada a través de la Serranía de Ronda. Unas circunstancias que, en el caso de los artistas, favorecía que se dedicaran a la representación de cuánto descubrían.

Sin ahondar en la importancia del viaje durante el XIX y sus antecedentes en el grand tour, sí es necesario resaltar cómo en la segunda década del siglo la península Ibérica aún permanecía al margen de este recorrido, hasta que la sensibilidad romántica concedió valor a la diferencia española. A partir de entonces, se hizo constante la demanda de representaciones de paisajes y personas para la ilustración de libros de viajes, la proyección de imágenes en los salones burgueses europeos y la reproducción de estampas que se incluyeran en los álbumes de moda (Pardo González, 2003).

A esto se añade que la singularidad del Campo de Gibraltar reclama su representación, manteniendo aún hoy esa capacidad para maravillar que tanto se apreció artísticamente en el siglo XIX. Pero, aunque es cierto que las imágenes románticas se caracterizaron por la subjetividad y en el caso del Estrecho se promovió una apariencia orientalista, los dibujos de Ender buscan objetividad descriptiva, que segura- 


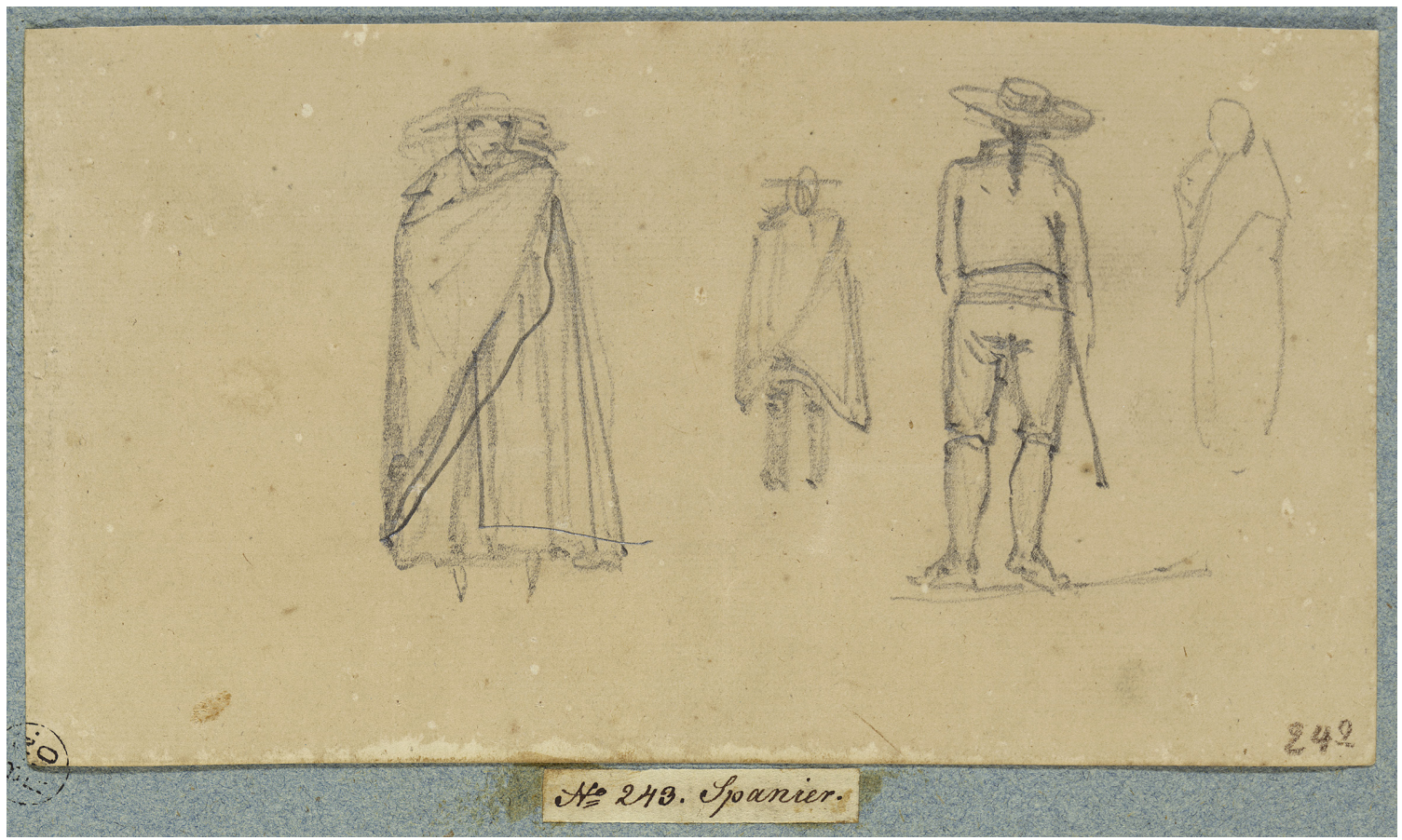

3. T. Ender, Españoles, 1817. BNB

mente se justifica por las finalidades de la empresa oficial de la que formaba parte.

Fueron muchos los artistas que realizaron representaciones del entorno. Repasando solo las dos décadas siguientes a la visita de Thomas Ender, recorrieron el territorio dibujando y pintado, el alemán Wilhem Gäil; los ingleses Richard Ford, Joseph Mallord W. Turner o David Roberts. También el francés Louis Auguste de Sainson, que participó en un viaje de cierta semejanza al de Ender, pues acompañaba a una expedición hacia el Pacífico Sur ${ }^{3}$.

El proceso de trabajo de todos los pintores que reprodujeron este entorno incluía el tipo de bocetos rápidos que realizó Thomas Ender. Visiones instantáneas que en algunos casos hubo tiempo de detallar más, pero con frecuencia estaban destinados a componer un repertorio de imágenes objetivo y archivable. Un mosaico al que recurrir pasado el tiempo, cuando los artistas, ya de vuelta en el estudio, se ocuparan de la composición de obras más complejas, principalmente al óleo, o para dar a la estampación, y necesitasen refrescar la memoria con los fragmentos que les impresionaron durante el viaje. Considerando, desde luego, que en 1817 los pintores aún no contaban con la fotografía como herramienta en su proceso de trabajo.

No obstante, desconocemos la mayoría de esos dibujos o acuarelas, por lo que tal excepcionalidad concede un inusitado valor a los bosquejos de Ender, tanto como a los que Eugène Delacroix insertó en su cuaderno de viaje quince años después, en 1832, cuando desembarcó brevemente en Algeciras mientras la tripulación del barco que le conducía a Tánger se aprovisionaba de víveres. También el pintor francés formaba parte de una misión diplomática, acompañando al conde de Mornay durante su visita al sultán de Marruecos. Su travesía por el Atlántico requirió de varias escalas en ciudades españolas como Cádiz, Sevilla y finalmente Algeciras, creando imágenes que comparten con las de Ender el hecho de ser apuntes de viaje, no obras terminadas. Aunque Delacroix, debido a la imposición de una cuarentena, solo pudo ver desde la playa el desenvolvimiento de la gente y eso fue lo que más captó su atención, los tipos humanos que le hacían revivir los modelos goyescos, su apariencia y atavío, como narra en cartas y en el texto que ilustra con rápidos trazos de acuarela (Delacroix, 1984). 


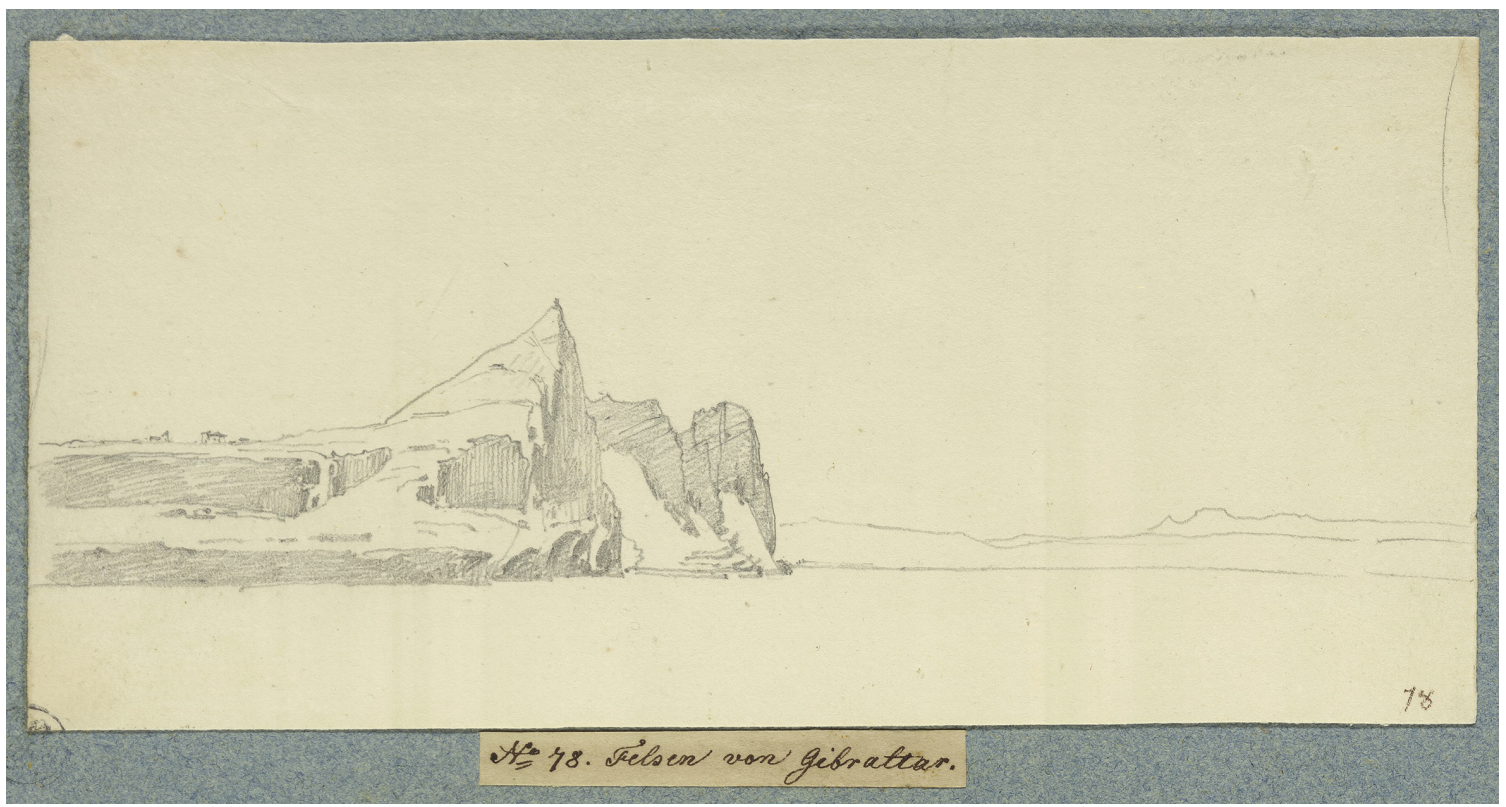

4. T. Ender, Peñón de Gibraltar, 1817. BNB

Sin embargo, Ender aprovecha su estancia más larga para elevar la mirada. Aunque ello no impide que se detenga a observar el atuendo que caracteriza a los españoles, especialmente la capa [3] y, quizá por petición de los naturalistas a los que acompañaba, retrata a los singulares monos del Gibraltar que tanta sorpresa solían causar a los visitantes del Peñón (Dorao Orduña, 1989).

Durante más de un mes tuvo tiempo de reproducir paisajes de amplísimos horizontes, hitos geográficos, tipos humanos y escenarios arquitectónicos.

La búsqueda de verosimilitud es el primer rasgo común que se encuentra en la colección de dibujos de Ender. Es el observador que cumple una función, la de documentar el viaje, cuando aún no se habían instalado en las representaciones de paisajes los recursos plásticos propios de la retórica sublime. Teniendo en cuenta que el entorno natural del Estrecho es lo suficientemente pintoresco sin necesidad de realzarlo con deformaciones, el ojo del artista capta enseguida su valor. Un ejemplo de ello es la insistencia en dibujar las altísimas paredes del Peñón, como se advierte en los dos apuntes señalados con el mismo título y número 81 (Zuckerhut von Gibraltar) y en el n. ${ }^{\circ} 78$ (Felsen von Gibraltar) [4].
La segunda característica es su acercamiento superficial a la realidad de Gibraltar y de España. Incluso analizando las composiciones más complejas de otras acuarelas del pintor que no pertenecen a esta colección brasileña, como las vistas de la ciudad de Gibraltar y de su mercado (Benady, 1996), ningún dato indica un diálogo deliberado del artista con la población. Se trata más bien de la mera observación curiosa pero distanciada, quizá condicionada por la barrera que le suponía no hablar español ni inglés.

Es obvio que Ender no muestra el característico interés hispanista que buscará un conocimiento profundo de la historia, sociedad y cultura del país desde los años cuarenta. Pero sus circunstancias tampoco le hacen pretender, como a tantos otros viajeros y dibujantes, la confirmación de los tópicos que les habían impulsado a visitar esta tierra, para lo que seleccionaban intencionadamente el tipo de individuos que incluían en las pinturas. Él solo está de paso y aprovecha la oportunidad que le ofrece esta parada técnica durante el viaje, aunque coincide con los demás, como norma regular de los paisajistas, en la representación de figuras a pequeña escala con el fin de dotar al paisaje de argumento literario.

Por ejemplo, en el dibujo n. 102 (Baadeplatz von Gibraltar), aparecen unos hombres en la orilla del mar, entre 


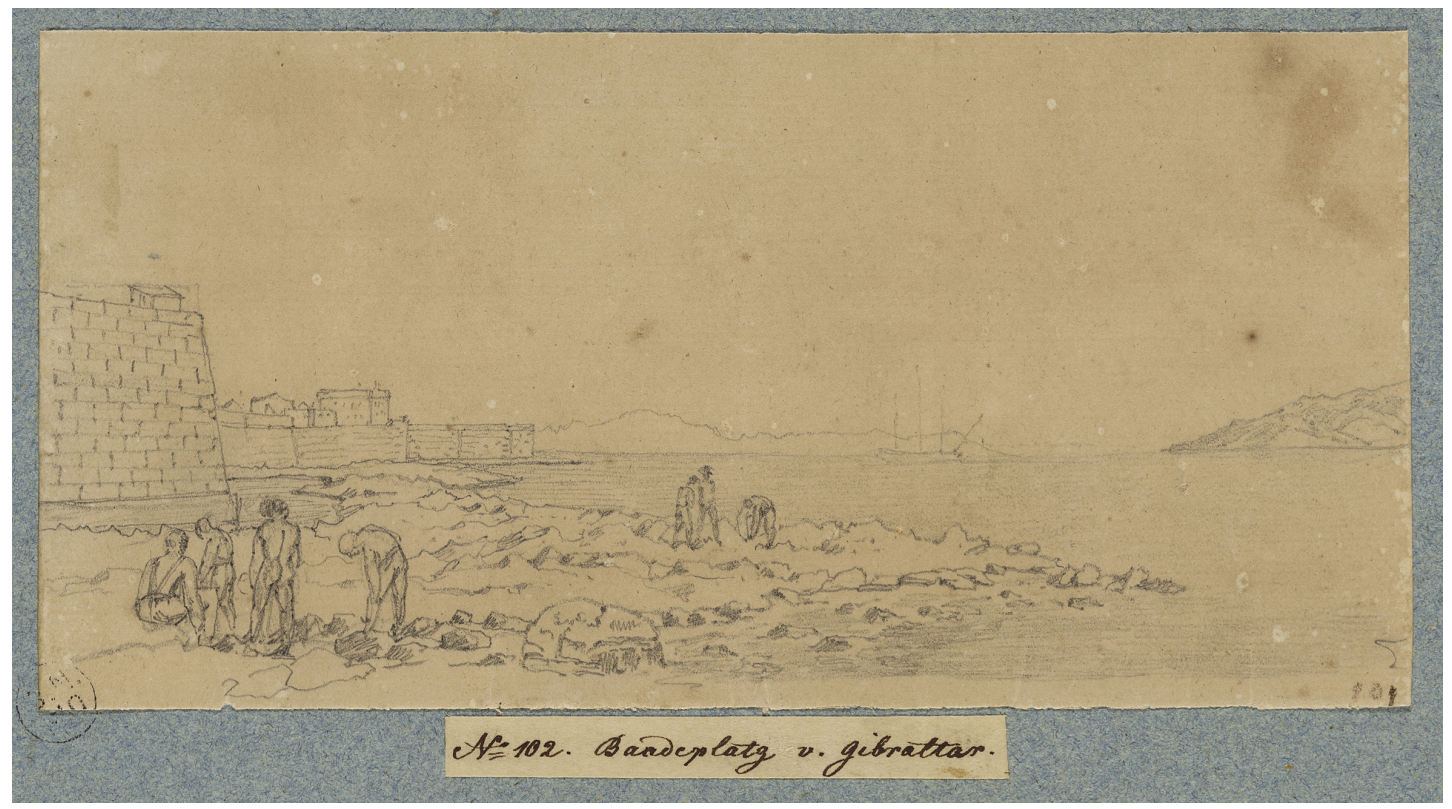

5. T. Ender, Lugar de baños de Gibraltar, 1817. BNB

las piedras que hay al pie de la muralla, con los montes de África al fondo y Algeciras a la derecha. Muestran diferentes posturas y están más o menos vestidos, pero todos vueltos de espaldas y sin revelar sus rostros. Podrían ser pescadores realizando cualquier faena marisquera, aunque dado que el título en alemán sugiere que es un lugar para el baño, también podrían ser los militares ingleses dispuestos a nadar en la playa [5].

Y en el n. 101 (Hütte vines spanischen Landmann a. d. Gebirge von Tariff), a pesar de lo somero y rápido de los trazos, ni siquiera ha caracterizado la indumentaria del campesino sentado ante la choza, evidenciando un mayor interés por el ambiente, especialmente la parra que da sombra delante de la puerta [6].

Por último, es manifiesto el protagonismo de los barcos en el imaginario artístico y documental de Ender. Por razones que parecen obvias, pues tenía 20 años, seguramente se trataba de su primera gran travesía y a la expectación que esta aventura le produjera se añadió la estancia durante semanas en un puerto y una bahía de tal tránsito y variedad de naves.

Insiste en repetir las representaciones de las fragatas «Austria» y «Augusta», con las que llegó la expedición desde Trieste. A veces en elegantes vistas desde la distancia y otras, deteniéndose en el detalle de sus cubiertas y bodegas, que muestra vacías o bien animadas con el baile y la música [7].

En definitiva, las aguas de sus paisajes se pueblan con todo tipo de embarcaciones como complemento indispensable de las marinas y también a modo de repertorio archivable para futuras composiciones, como al dejar constancia de los barcos de faena en el dibujo n. 83 (Barken in der Rhede von Gibraltar gesehen).

Ahora bien, a pesar de la abundancia de imágenes decimonónicas conservadas del Campo de Gibraltar, las representaciones arquitectónicas no son frecuentes. En las vistas generales de Algeciras es raro que se refleje con detalle la arquitectura doméstica. Si acaso algo de la religiosa, las arruinadas murallas medievales y, siguiendo las indicaciones de Richard Ford, el acueducto construido a fines del siglo XVIII (Ford, 1988).

Es presumible que a los ojos de unos viajeros que suelen incluir en sus itinerarios ciudades cercanas y tan monumentales como Sevilla, Granada, Málaga, Ronda o Cádiz, las edificaciones del Campo de Gibraltar no parecieran singulares, extraordinarias ni dignas de ser pintadas. Hay alguna excepción, claro, como la representación de la capilla 


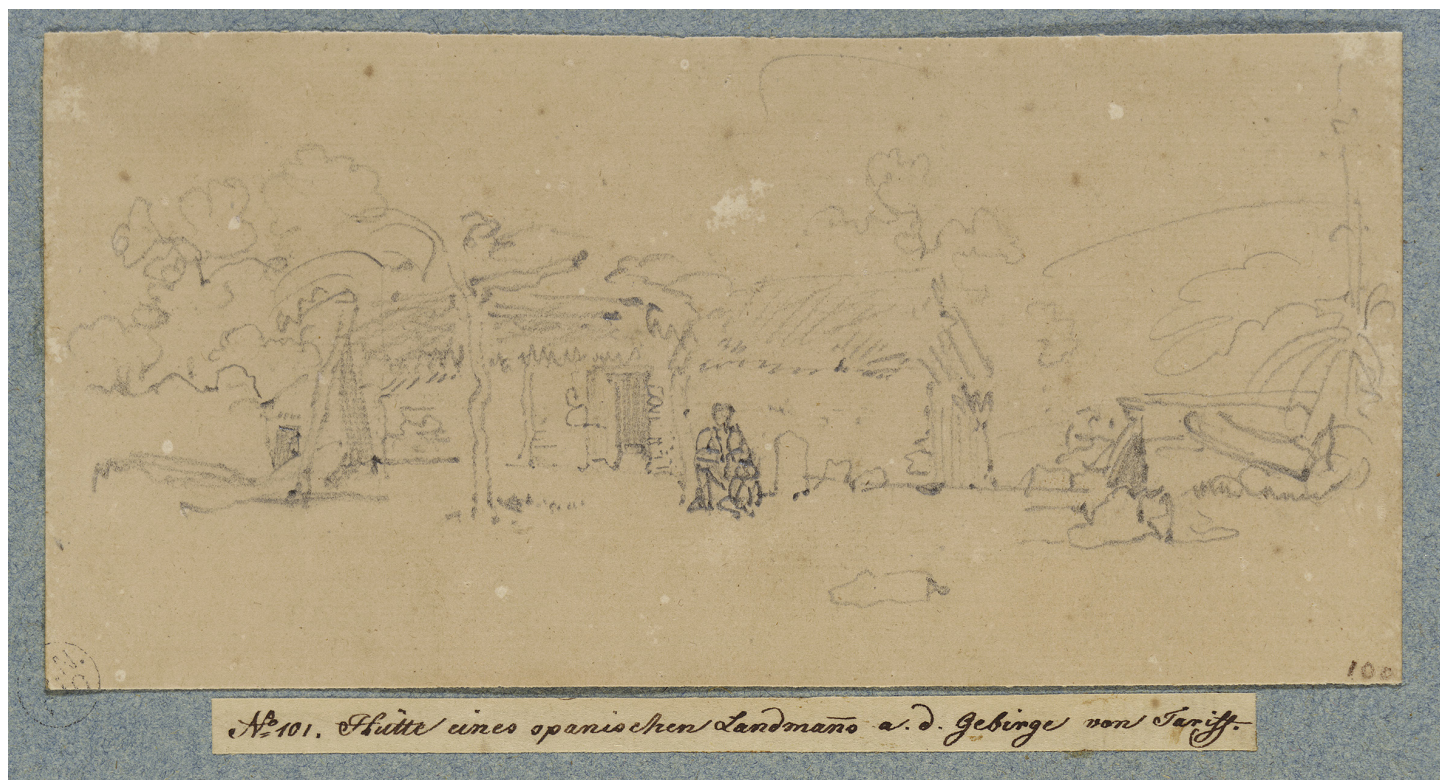

6. T. Ender, Choza con vides de un campesino español en las montañas de Tarifa, 1817. BNB

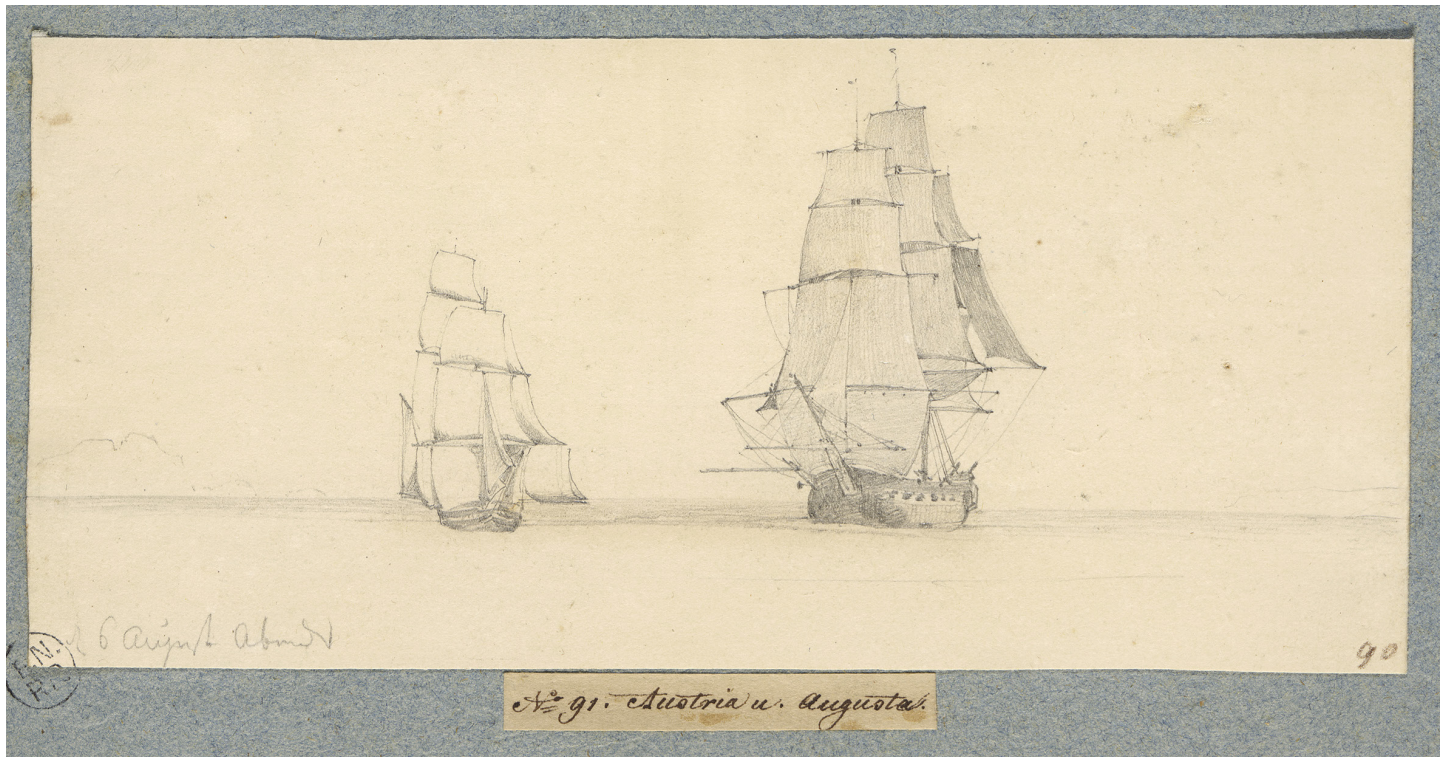

7. T. Ender, Austria y Augusta, 1817. BNB

del Cristo de la Alameda en la estampa titulada Une église à Algésiras del ya mencionado Louis Auguste de Sainson.

Porque la ilustración de 1807, Vista en perspectiva de la nueva Plaza del Rey en Algeciras, no es obra de viajeros sino un instrumento de propaganda política que dibujó el coronel de artillería Joaquín Dolz y fue grabada por Tomás López Enguidanos, para informar sobre la reurbanización ordenada por el General Castaños del espacio de mayor 


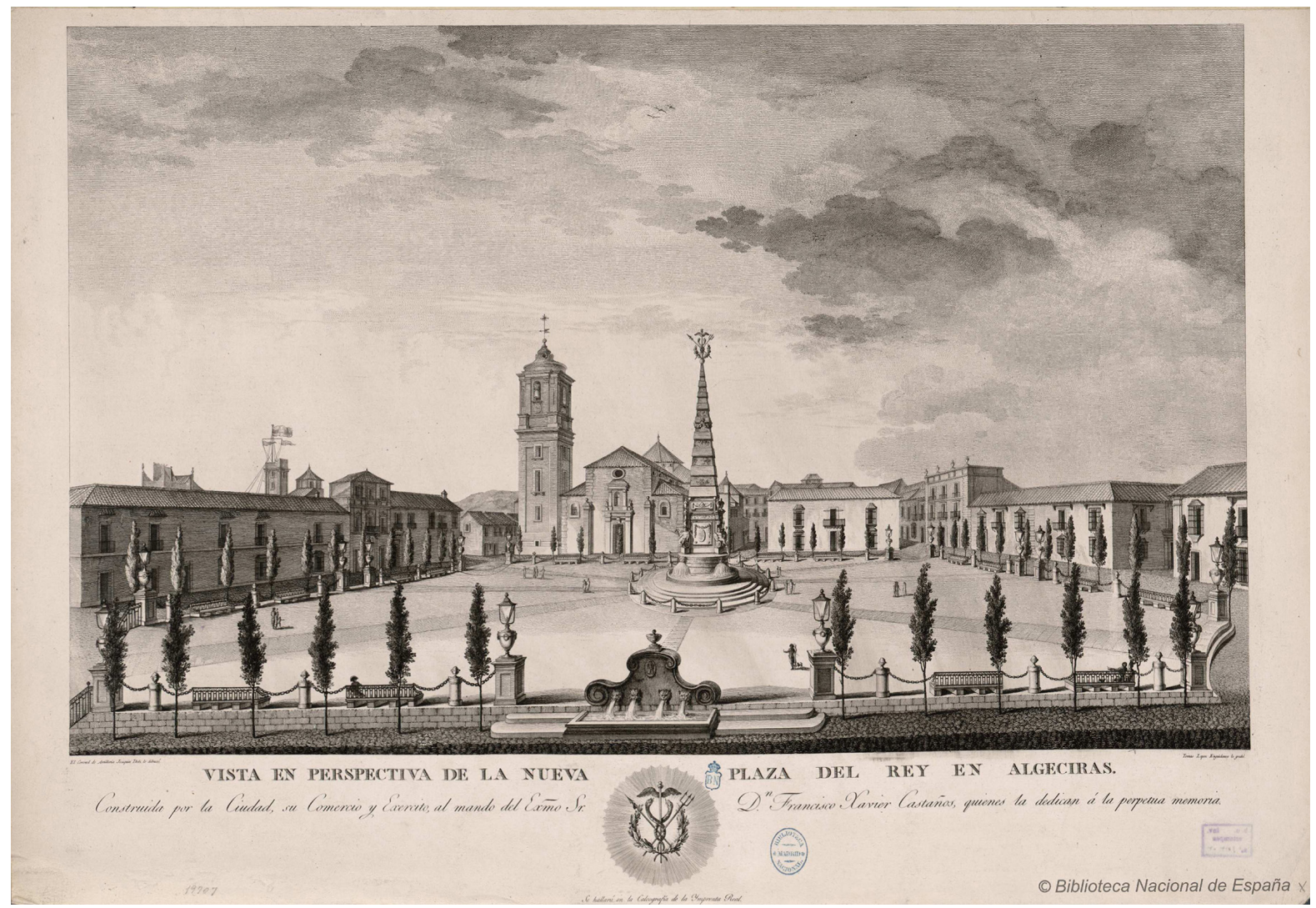

8. J. Dolz y T. López Enguidanos, Vista en perspectiva de la nueva Plaza del Rey en Algeciras, 1807. Biblioteca Nacional de España

representatividad de la población (Aranda y Quiles, 1999). Aunque tiene el valor de ofrecer la primera descripción gráfica conocida de la arquitectura algecireña y resulta muy útil en su comparación con uno de los más interesantes dibujos realizados por Thomas Ender [8].

Naturalmente, podemos complementar estas imágenes con las dos relaciones escritas más cercanas en el tiempo a la visita de Ender. La primera es la descripción del dramaturgo y poeta Leandro Fernández de Moratín, que conoció Algeciras en diciembre de 1796 y se refiere a esta población de unos ocho mil vecinos como «un gran lugarote, con dos plazas y dos o tres calles buenas; lo demás, todo es casillas pobres, cuestas, lodo (...) y majos con sus capotes y sus monteritas de terciopelo, muy chiquititas y muy adornadas de borlas y alhamares y madroños de seda» (Fernández de Moratín, 1867).

Una impresión que corrobora el viajero norteamericano Robert Semple en 1805, considerando que "su cons- trucción, a excepción de unas cuantas casas pertenecientes a la gente principal, tampoco demasiado buenas, es pobre (...). Sin embargo, las calles no son muy estrechas, las casas están hechas de piedras que, aunque sin labrar, les dan una mejor apariencia que las chozas de paredes de barro y techumbre de paja tan abundantes en las provincias occidentales» (Semple, 1805).

Es decir, a ambos escritores les gusta la amplitud y el alineamiento de las calles, fruto del diseño racionalista de los ingenieros militares del siglo XVIII y alejado del urbanismo medieval característico de las villas y ciudades del entorno, que los viajeros no aprecian demasiado.

Pero ninguno llega a valorar del todo las viviendas, seguramente porque no muestran dimensiones monumentales, ni fachadas de piedra con referencias clasicistas o, a lo sumo, con portadas barrocas -aunque para esa fecha el estilo ya estuviera muy denostado-. Las casas principales 


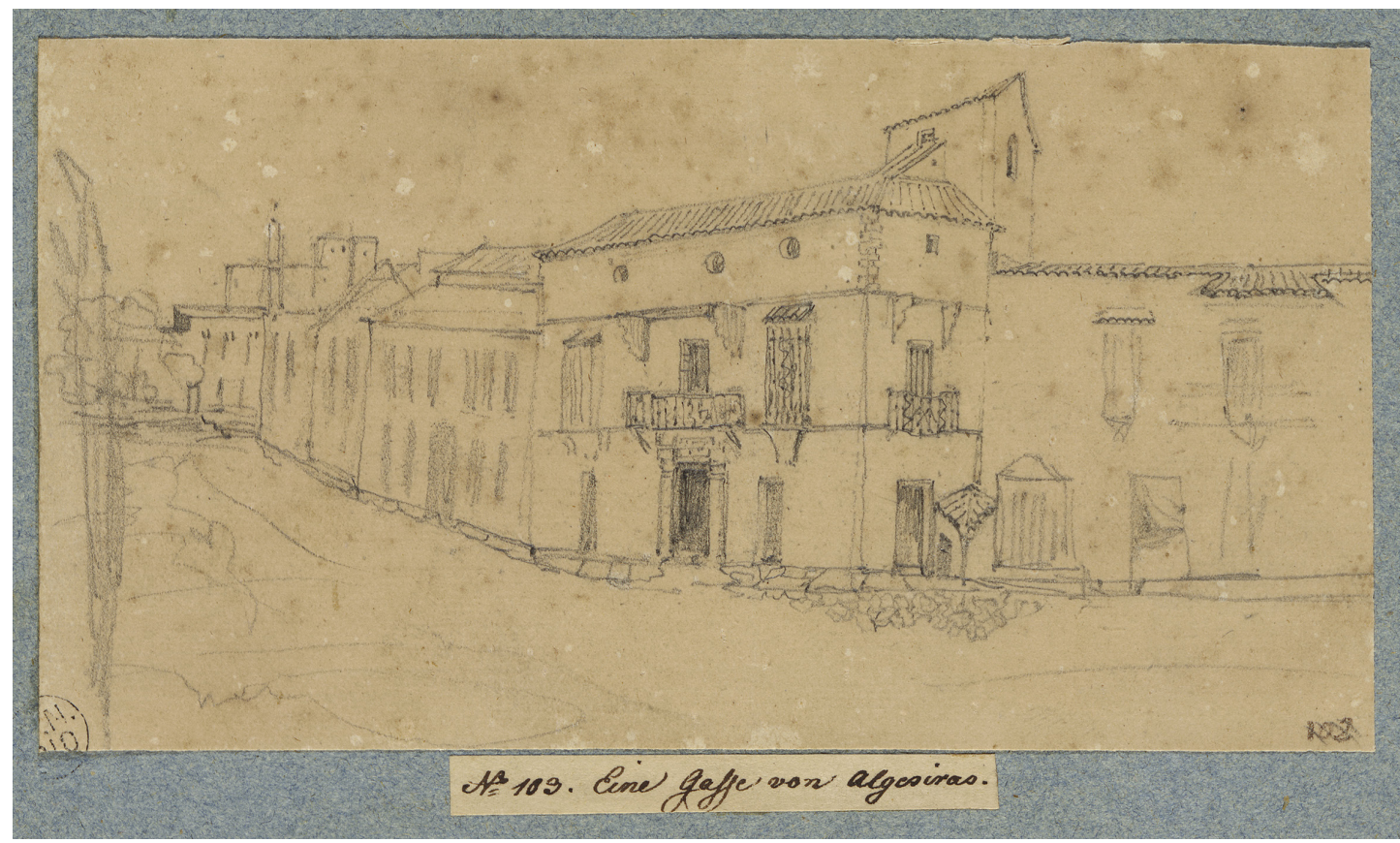

9. T. Ender, Una calleja de Algeciras, 1817. BNB

de Algeciras responden al tipo tradicional de la arquitectura vernácula en la región y a la composición socioeconómica de sus vecinos, entre los que no hay nobles ni representantes de importantes instituciones, más allá de la capitanía general del Campo de Gibraltar. De hecho, entre los pocos habitantes que no vivían en barracas, casas bajas o patios de vecinos, sino en construcciones de calidad acorde con su posición adinerada, abundaban quienes habían hecho su fortuna alternando el comercio y el corso.

Los planos que desde el siglo XVIII venían representando la ciudad muestran cómo las casas más importantes contienen el tradicional patio con crujías alrededor. En la Plaza del Rey (Alta) descubrimos sus fachadas de ladrillo enfoscado y dos o tres alturas, la mayoría cubiertas con tejado, además de alguna con pretil y azotea. Las puertas de ingreso se desdibujan por su sencillez, pero se aprecia un esmerado orden en la distribución de balcones y ventanas, que están cubiertas con cierros de rejería.

Pues bien, una de esas casas captó la atención de Thomas Ender, se detuvo a dibujarla y la incluyó en su álbum con el n. ${ }^{\circ} 103$ (Eine gasse von Algesiras) [9]. Estaba situada en la calle Real, que con el tiempo se ha llamado también
Cánovas del Castillo, Eduardo Dato y aún hoy conserva el nombre de José Antonio -es el número 9-.

Aunque Ender la defina en su título como calleja o callejón, era una de las vías más importantes de la población, que unía desde el medievo las puertas de la Mar y de Gibraltar. Seguramente el pintor caminó por ella desde el puerto, después de atravesar la Plaza Baja o de las verduras, para llegar hasta la Plaza Alta o de la iglesia, es decir, el recorrido imprescindible que debía cumplir cualquier visitante curioso.

El austríaco subiría la pronunciada pendiente y cuando llegó al tramo llano, donde quizá sus acompañantes de más edad tuvieran que pararse a recuperar el aliento, dibujó la casa con la fachada de más empaque encontrada durante su recorrido. Lo llamativo es que pocos metros más allá se abre la Plaza Alta, muy parecida a la imagen que nos transmite la estampa de 1807, más distinguida y cuyos árboles él mismo insinúa al fondo de su dibujo junto a la espadaña de la Capilla de Europa, pero no la representó.

La planta de la vivienda, que Ender destaca del resto de la calle a través de una mayor atención a los detalles. ya aparecía señalada un siglo antes, en el «Plano de la Ciudad de las Algesiras con el Proyecto de las Calles que se han de 


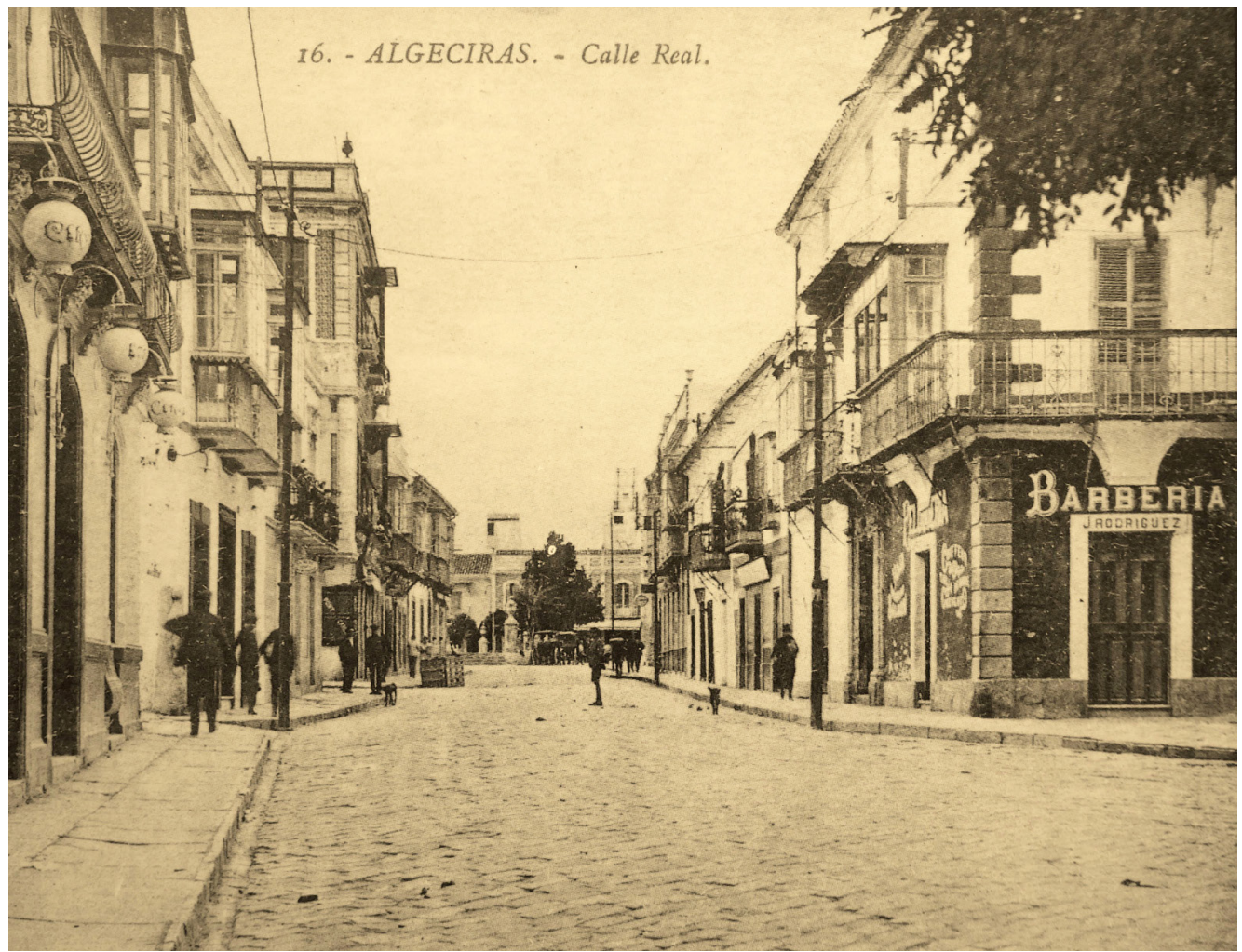

10. Calle Real, Algeciras. Principios del siglo XX. Col. Particular

formar para su nueva Población», de enero de 1724 (Aranda y Quiles, 1999), donde se indicaba que su propietario era Alonso de Lucena. Seguirá constantemente representada en los demás planos del siglo XVIII, frente a la embocadura de la calle Bailén, marcando ya una pequeña esquina. Hasta que unos cien años después de la visita del pintor austríaco a Algeciras, la vivienda aparece fotografiada desde una perspectiva diferente. Entonces observamos que ha sufrido algunos pequeños cambios, pero en esencia, se trata de la misma construcción que fue demolida a mediados del siglo XX.

Ender dibuja un edificio de tres alturas y la característica torreta desde la que vigilar los negocios de la mar, que se extiende justo detrás. La puerta principal con sus dos pilastras adosadas y un entablamento bajo el balcón principal del primer piso se mantuvieron siempre, incluso su tejaroz de pizarra. Constituiría la entrada hacia el zaguán y el patio desde donde se articula el resto de los espacios, mientras que las habitaciones que dan a la calle muestran entradas independientes porque se trataría de tiendas, talleres y una barbería ya en el siglo XX [9] y [10].

Con el paso del tiempo permanecieron las cantoneras de sillares y los pequeños huecos de aireación del último piso, que estaría destinado a almacén. Sin embargo, las ventanas con cierro del piso principal se sustituyeron por balcones que ocupaban toda la fachada.

Todo ello nos indica la fidelidad de la representación, que constituye la esencia del trabajo de Thomas Ender y cumple el encargo principal de documentar a través de las imágenes. Su mirada seleccionadora se convierte en el espejo que refleja una casa, una calle cualquiera de la población de Algeciras, atrapando un instante, fijándolo para siempre. 


\section{Notas}

1 Faltan las piezas 85 (camarote del Dr. Martius en la fragata Austria) y 171 (creolen), lo que produce una alteración de la numeración. En 1955 se adquirieron para la colección dos acuarelas: Aspecto do bordo, donde se ve el interior de la fragata Austria con varios pasajeros y los científicos Spix y Martius; e Interior del dormitorio de Barao von Hugel, miembro de la embajada austríaca en Río de Janiero (Fonseca F. Cunha, 1968: 15).

2 Se trata de obras conservadas en diferentes colecciones: Vista de Gibraltar desde el norte (26 × $37.8 \mathrm{~cm})$, Vista de Gibraltar (28 x $47 \mathrm{~cm})$, Mercado de Gibraltar $(16.2 \times 22.8 \mathrm{~cm})$ y El Peñón de Gibraltar $(12.5 \times 18.5 \mathrm{~cm})$.

3 Louis Auguste de Sainson (1801-1887) fue el pintor nombrado para ilustrar la expedición dirigida por Dumont d'Urville al Pacífico Sur (Australia Nueva Zelanda y Nueva Guinea. Salieron de Toulon en abril de 1826 y volvieron a Marsella en febrero de 1829. Las imágenes fueron publicadas en un lujoso atlas entre 1830 y 1835 editado por Tartu con litografías a cargo de Lemercier y Leborne.

\section{Bibliografía}

ARANDA BERNAL, Ana y QUILES, Fernando (1999), Historia urbana de Algeciras. Siglos XVIII al XX, Consejería de Obras Públicas, Junta de Andalucía, Sevilla.

BENADY, Tito (1996), The Streets of Gibraltar, Gibraltar Books.

DELACROIX, Eugène (1984), Viaje a Marruecos y Andalucía. Cartas, acuarelas y dibujos (1. a ed. 1832), Olañeta, Barcelona.

DORAO ORDUÑA, Marisol (1989), «Pan y naranjas. Seis viajeras inglesas en el Gibraltar del siglo XIX», Almoraima. Revista de estudios campogibraltareños, n. ${ }^{\circ}$, Mancomunidad de Municipios del Campo de Gibraltar, Algeciras.

FERNÁNDEZ DE MORATíN, Leandro (1867), Obras póstumas. Tomo II, Madrid.

FONSECA F. CUNHA, Lygia (1968), Thomas Ender. Catálogo de desenhos, Biblioteca Nacional, Coleçao Rodolfo García, Río de Janeiro.

FORD, Richard (1988), Manual para viajeros por Andalucía y lectores en casa (Reino de Sevilla), Turner, Madrid.

LEITE, José Roberto Teixeira (1988), Dicionário crítico da pintura no Brasil, Artlivre, Río de Janeiro.

PARDO GONZÁLEZ, Juan Carlos (2003), «Estampas románticas de Castellar y otras poblaciones campogibraltareñas», Almoraima. Revista de estudios campogibraltareños, n. ${ }^{\circ}$ 29, Mancomunidad de Municipios del Campo de Gibraltar, Algeciras.

SEMPLE, Robert (1. ${ }^{a}$ ed. 1805, 2. ${ }^{a}$ ed. 1807), Observations on a Journey througt Spain and Italy to Naples, and thence to Smyrna and Constantinople, C. and R. Baldwin, Londres. 